\title{
O GIRO LINGUÍSTICO E A NORMATIZAÇÃO CONSTITUCIONAL NO CASO CONCRETO: CONFORMAÇÃO NA DECISÁO QUE DETERMINOU O SERVIÇO DE TELE-ENTREGA DE RESTAURANTE EM SHOPPING NO PERÍODO DE PANDEMIA DO CORONAVÍRUS
}

\author{
LINGUISTIC TURNING AND CONSTITUTIONAL \\ STANDARDIZATION IN THE CONCRETE CASE: \\ CONFORMATION IN THE DECISION THAT DETERMINED \\ THE RESTAURANT TELE-DELIVERY SERVICE IN SHOPPING \\ IN THE CORONAVIRUS PANDEMIC PERIOD
}

HILBERT MAXIMILIANO AKIHITO OBARA ${ }^{1}$

\section{RESUMO}

O artigo objetiva analisar a decisão judicial que, em tempos de pandemia do coronavírus, permitiu a um restaurante, estabelecido dentro de um shopping, realizar serviços de tele-entrega. Havia proibição de funcionamento de shoppings e permissão de alguns serviços de restaurante. Inexistia regramento específico para prestação dos mesmos serviços de restaurante dentro dos shoppings. Diante de dispositivos textuais, constantes de decretos municipais, aparentemente conflitantes, com omissão da situação específica, a decisão permitiu um dos serviços. 0 estofo teórico da decisão tem na condição de possibilidade hermenêutica filosófica, no dasein, a relevância do texto e do contexto para a adjudicação de sentidos, permitindo a normatização constitucional no caso concreto, identificando-a na decisão. O procedimento metodológico parte da revisão bibliográfica para estudo do caso paradigma. 0 estudo revela a possibilidade da construção jurídica que, partindo sempre de uma premissa racional e progressiva dos direitos humanos e fundamentais, possibilita o sentido constitucional e democraticamente adequado. Desse modo, é descartado tanto o aprisionamento do legalismo estrito quanto a aposta no decisionismo.

1 Professor do PPGD e Graduação em direito da Unilasalle. Mestre e doutor em direito pela Unisinos. Juiz de Direito da $5^{\text {a }}$ Vara da Fazenda Pública de Porto Alegre do Tribunal de Justiça do Estado do Rio Grande do Sul. ORCID: http://orcid.org/00000002-4144-3620. E-mail: hilbert.obara@unilasalle.edu.br 
PALAVRAS-CHAVE: Normatização constitucional. Conflito aparente de regras. Análise de decisão judicial.

\section{ABSTRACT}

The article aims to analyze the court decision that, in times of the coronavirus pandemic, allowed a restaurant, established inside a shopping mall, to perform tele-delivery services. There was a ban on the operation of shopping malls and the permission of some restaurant services. There was no specific regulation for the operation of the same restaurant services inside the malls. Faced with textual provisions, appearing in municipal decrees, apparently conflicting, omitting the specific situation, the decision allowed one of the services. The theoretical basis of the decision is in the condition of philosophical hermeneutic possibility, in the dasein, the relevance of the text and the context for the adjudication of meanings, allowing the constitutional standardization in the specific case, identifying it in the decision. The methodological procedure starts from the literature review to study the paradigm case. The study reveals the possibility of legal construction that, always starting from a rational and progressive premise of human and fundamental rights, makes possible the constitutional and democratically adequate sense. In this way, both the imprisonment of strict legalism and the bet on judicial arbitrariness are ruled out.

KEYWORDS: Constitutional regulation. Apparent rules conflict. Judicial decision analysis.

\section{INTRODUÇÃO}

São diversos os textos legislativos produzidos para tratar das situações decorrentes da pandemia do coronavírus. Não raro é identificada a limitação do texto legal para a solução dos problemas concretos, como ocorre no caso tratado pela decisão analisada. A fundamentação da decisão não está amparada nem na subsunção e nem em métodos interpretativos para arrancar sentidos do texto legal ou pseudo princípios acobertadores do arbítrio judicial. A decisão judicial não pode estar limitada pelo texto legal, sob pena de, como na situação analisada, não permitir respostas aos anseios sociais. 0 caso revela a incompletude do texto e, portanto, a impossibilidade da aplicação subsuntiva da lei, como no sonho liberal-burguês do juiz boca da lei. Da mesma forma, não são admissíveis decisões ancoradas em sentidos subjetivamente alcançáveis de forma arbitrária, ainda que pseudo jurídicas por estarem vinculadas a instrumentos de interpretação e/ou pseudo princípios que escondem o arbítrio judicial, apontando para caminhos que não são necessariamente jurídicos e democraticamente progressivos. Os dois percursos são constitucionalmente inadequados em razão da insuficiência do primeiro e da ausência de limites do segundo.

O escrito traz a investigação dos fundamentos teóricos da decisão provisória de urgência antecipada que permitiu a um restaurante, estabelecido dentro de um shopping, a reabertura de um de seus serviços, no período da pandemia do coronavírus. A administração do shopping, da leitura da legislação municipal relacionada à questão, entendeu que deveria barrar a atividade comercial do restaurante. $\mathrm{E}$, de outro lado, os representantes do restaurante entenderam que a mesma legislação municipal autorizava o serviço de tele-entrega (delivery) e pegue e leve (take away). Porém, a decisão construída constitucionalmente no caso concreto parece permitir apenas o funcionamento da tele-entrega em face do confronto dos textos legislativos e do respaldo dos direitos humanos e fundamentais. 
Está em exame o eventual respaldo teórico, hermenêutico-filosófico e constitucional para o resultado pragmático refletido na decisão analisada. A hermenêutica-filosófica é anterior ao direito, não ocupa o mesmo campo, tem objeto próprio e distinto, mas é condição de possibilidade, e, como tal, produz standards de racionalidade utilizáveis pelo direito. 0 dasein é limitador dos sentidos, impede o assujeitamento dos objetos, do sentido do texto, ao mesmo tempo em que também faz reconhecer que os sentidos não advém metafisicamente dos objetos, havendo a indispensabilidade do sujeito-intérprete, na inevitabilidade linguística. Então, no plano apofântico jurídico, a Constituição não é só texto escrito, mas também o é. A condição de possibilidade hermenêutica-filosófica, exige a ultrapassagem da paralisia objetificante, que tem a Constituição como mero texto escrito, cujos sentidos são pré-dados e, portanto, inaptos para alcançar os novos contornos de uma sociedade complexa em constante mutação. Do mesmo modo, impede que a Constituição seja assujeitada pelo intérprete. Quando a adjudicação de sentido da Constituição não pode ser solipsista, descabe ao intérprete arbitrariamente dar o sentido. Na proposta do artigo inexiste espaço tanto para o intérprete refém do texto quanto para aquele que tem o seu eu indevidamente agigantado. Necessário que os sentidos advenham do sujeito mas de conformidade com limitações advindas do contexto social-temporal, guiados pela tradição e história efeitual, na concretização da norma constitucional no caso concreto.

Não é dado na contemporaneidade uma cientificidade pura, um resgate do mundo do direito completamente dissociado da sociedade. O jurista não conjuga apenas leis e as analisa em tese. 0 jurista deve ser despertado do seu sonho de direito puro, estéril, imune aos fatos. Esse resgate valoriza o mundo prático do direito, o mundo da vida, onde as produções jurídicas, o agir dos operadores do direito não pode ignorar a eficácia pragmática. 0 trabaIho traz vetores de racionalidade filosóficos aptos a contribuir para que o direito atente para as consequências fáticas, primando por um delineamento constitucional e democrático. 0 saber jurídico parte dos direitos humanos e fundamentais para a solução construída de conformidade com as especificidades de cada caso.

$\mathrm{Na}$ situação analisada na decisão o óbice integral de todas as atividades do restaurante deixaria-o em tratamento desigualitário em relação aos seus concorrentes, prejudicando sobremaneira o mesmo e consequentemente todos aqueles que dependem do seu funcionamento. Por outro lado, a liberação dos mesmos serviços que eram desempenhados pelos demais concorrentes do ramo, estabelecidos fora do shopping, seria apto a gerar uma movimentação de pessoas e funcionários indesejáveis para o momento, potencializando o risco de agravamento dos problemas da pandemia, com maior contaminação e aumento do número de doentes e mortes. Por isso, a normatização constitucional no caso concreto reconheceu a possibilidade da empresa dar vazão aos seus objetivos comerciais somente pela modalidade de tele-entrega, permitindo a concorrência, sem colocar em risco outros interesses relevantes da sociedade defronte ao problema da pandemia do coronavírus. Foram conjugados os interesses constitucionais da liberdade comercial da empresa com a necessidade de respeito à saúde e à vida dos cidadãos.

Os dois textos normativos municipais alcançaram a sua dimensão factual de conformidade com a Constituição. Quando o julgado permitiu que os textos, na expressão gadameriana, trouxessem a sua verdade, houve o respeito à tripartição de poderes, posta como cláusula pétrea constitucional. Se é possível identificar um destaque da função judiciária, 
não o é em postura ativista, sobrepondo-se à função executiva ou legislativa. De certo que a supremacia do Poder Judiciário, a aposta no seu protagonismo, não encontra respaldo em um regime democrático. 0 pressuposto isonômico da cidadania não permite a deslegitimação no exercício do poder, não permite que ninguém, que qualquer pessoa ou instituição avoque para si a tarefa de implementar o bem comum (conforme a sua noção, não necessariamente compartilhada, portanto, própria, de bem comum), submetendo a todos os demais. Verificável da decisão em comento que o julgador no exercício de sua função, dentro dos limites constitucionais, normatiza no caso concreto, trazendo efetividade na busca do contorno democrático desejado socialmente.

\section{A DECISÃO ANALISADA}

A decisão em questão foi dada liminarmente, em um pedido provisório de urgência constante de uma ação ordinária ajuizada na quinta Vara da Fazenda Pública da Comarca de Porto Alegre do Tribunal de Justiça do Estado do Rio Grande do Sul, cujo teor foi:

"Vistos.

Trata-se de ação ordinária, em que a parte autora, qualificada como restaurante localizado no interior das dependências do Barra Shopping de Porto Alegre, narra que foi notificada pela administração do shopping sobre fechamento de sua atividade comercial, em decorrência das medidas adotadas pelos Decretos Municipais nº 20.534/2020 e 20.540/2020 à prevenção da COVID-19. Sustenta que o fato de o restaurante autor estar localizado no interior do shopping não é circunstância impeditiva para o funcionamento na modalidade delivery (tele-entrega) e take away (pegue e leve). Fundamenta o pedido com base no art. 11, incisos XIV e XV, e $\S 2^{\circ}$, do Decreto Municipal n $20.534 / 2020$. Requer a tutela provisória de urgência para autorizar a reabertura da empresa autora para as operações sob sistema de delivery e take away, ressalvada alteração no sistema de atendimento em caso de edição de norma mais benéfica, sob pena de aplicação de multa diária. Anexou documentos.

É o relatório.

Decido.

Inicialmente, registro que a petição inicial traz elementos conformadores de pedido de tutela provisória de urgência antecipada, sendo assim recebida por aplicação do princípio da fungibilidade das tutelas de urgência. Outrossim, seguirá o procedimento incidente, em face do descumprimento do par. $5^{\circ}$ do art. 303 do CPC.

O Município procurou disciplinar procedimentos para o período de pandemia. 0 enfrentamento da crise gerou situação de calamidade pública reconhecida nos decretos municipais $20.534 / 2020$ e 20540/2020. Não coloco em dúvida que o risco que a pandemia do coronavírus criou para a vida e para a saúde da população exige medidas urgentes e drásticas, inclusive limitando a atividade comercial. Essas medidas estão previstas nos decretos referidos.

Nenhum dos decretos mencionados autoriza expressamente o funcionamento de restaurantes no interior de shopping centers. Muito antes o contrário, a leitura do artigo 13 do Decreto Municipal $n^{\circ} 20.534 / 2020$ determinou o não funcionamento dos shopping centers, 
excepcionando alguns serviços considerados essenciais pela autoridade municipal, dentre os quais não está a autora, do ramo de restaurante. 0 funcionamento dos restaurantes estaria limitado ao sistema de tele-entrega (delivery) e pegue e leve (take away), conforme o par. $2^{\circ}$, do art. 11 do mesmo decreto, com o que, na conjugação dos dois dispositivos, seria possível concluir (como fez o notificante do impedimento do desempenho da atividade), que o funcionamento dos restaurantes só pode ocorrer fora dos shoppings e no formato de tele-entrega (delivery) e pegue e leve (take away).

Ocorre que o sentido dos regulamentos municipais deve ser alcançado à luz da constituição. Se a autoridade municipal permitiu o funcionamento de outros restaurantes no serviços de pegue e leve (take away) e tele-entrega (delivery) há de ser verificada a possibilidade de estender os mesmos serviços para os restaurantes situados no interior dos shopping centers. Se algum desses serviços não for aumentar o risco de incremento da pandemia, quando realizado dentro do shopping, deverá ser estendido aos restaurantes dos shopping centers, em respeito ao princípio isonômico e da livre concorrência. De modo que o serviço de tele-entrega (delivery), por não ter qualquer elemento diferencial em relação ao que é prestado externamente aos shopping centers, por normatização constitucional contextual, deve ser permitido para a autora.

Volto a repetir que a prioridade constitucional, nesse período de crise, é a de proteção à vida e à saúde dos brasileiros. Então, o desempenho das atividades comerciais, em caráter excepcional, em face da calamidade pública, deve observância à não afetação dos direitos constitucionais fundamentais da vida e saúde. O regramento municipal é no sentido de evitar qualquer possibilidade de idas não imprescindíveis e de circulação e aumento de pessoas nos shopping centers, bem como a necessidade de mais funcionários do shopping para regular o recebimento dos consumidores. Então, a limitação do desempenho do serviço de pegue e leve (take away) faz prevalecer a segurança à saúde e à vida em detrimento do interesse comercial da autora, atendendo a regra do art. 13 do Decreto Municipal n 20.534/2020.

Os requisitos para a concessão da tutela provisória de urgência estão previstos no art. 300 , do CPC. São eles a probabilidade do direito e o perigo de dano. Pelo que dito acima está a demonstração do primeiro desses requisitos.

O segundo requisito, o perigo de dano, também está presente. A interpretação constitucionalmente inadequada que impediu o serviço de tele-entrega (delivery) é geradora de prejuízos financeiros presentes e futuros, danos potencialmente irreparáveis para a empresa autora.

Ante o exposto, DEFIRO PARCIALMENTE A TUTELA PROVISÓRIA DE URGÊNCIA para autorizar a reabertura da empresa autora (LOJA 2093-A "CHAMPANHARIA NATALICIO") tão somente para operações sob sistema de tele-entrega (delivery), sem prejuízo de alteração para regime mais benéfico ou mais rigoroso, inclusive com vedação de serviço, com a edição de novos decretos.

Na hipótese de descumprimento pelos réus, informe-se para fins de fixação de astreintes.

Defiro a gratuidade judiciária.

Citem-se e intimem-se, com urgência." 


\section{A RELAÇÃO DA FILOSOFIA COM O DIREITO}

A filosofia, a hermenêutica filosófica, está em nível anterior diverso do direito, com campos de estudo e atuação distintos. Há um duplo nível da fenomenologia, um anterior, estrutural, que é filosófico e um segundo apofântico, ornamental, de estruturas lógicas procedimentais e/ou argumentativas (STRECK, 2008, p. 132). Enquanto a primeira tematiza o campo do ser, pressuposto de todo conhecimento e de toda ciência, o segundo trata do ente, pressupondo a linguagem, mas utilizando o método para o aprofundamento de questões específicas, em uma práxis determinada (OLIVEIRA, 1996, p. 216). Enquanto a filosofia concentra seus esforços nos problemas da solução, as ciências buscam a solução dos problemas (STEIN, 2004, p. 135-136).

A autonomia de objetos não faz com que o direito seja indiferente à hermenêutica filosófica quando é acrescido o pressuposto comum empírico (STEIN, 2002, p. 100). A hermenêutica, na sua fusão de horizontes e condição de possibilidade compreensiva do ser (ser-aí), é pressuposto do saber científico, inclusive jurídico, com o que é capaz de exercer o papel de "guardiã" do conhecimento das ciências e do direito. É, então, proposto um Direito mais filosófico, onde toda produção jurídica deve respeitar a anterioridade epistemológica hermenêutica (STEIN, 2004, p. 126), em detrimento de arquétipos anteriores (STEIN,, 2002, p. 104), mormente do falso modelo jurídico da ilustração, baseado em princípios fixos e imutáveis, imunes ao tempo e à história (HOMMERDING, 2007, p. 42-43). A filosofia guardiã desempenha uma função cooperativa de aperfeiçoamento, na medida em que é apta a trazer o mundo vivido para dentro do Direito ( HABERMAS, 1989, p.18), proporcionando a necessária desobstrução para o encontro da produção jurídica com os dados sensíveis, com o sense data (STEIN, Ernildo, 2002, p. 112). O direito, desse modo, não pode ser imune à filosofia.

Os paradigmas filosóficos anteriores ao giro linguístico-ontológico, concebiam a linguagem como expressão da efetivação de uma essência ideal, quando é acesso à compreensão, acepção de mundo (GADAMER, 1999, p. 642) e exteriorização da razão (OLIVEIRA, 1996, p. 202-203). A teoria do conhecimento guiada pela metafísica relação sujeito-objeto², respalda a entificação do ser, conduzindo a um processo interpretativo guiado predominantemente pela objetividade do texto ou subjetividade do intérprete (STRECK, 2008, p. 128129), ignorando a diferença ontológica, por baseada em uma diferença entre subjetividade e objetividade transcendental, o que era impeditivo da cooperação da filosofia, da filtragem filosófica do direito (STEIN, 2002, p. 100). 0 direito, na visão criticada, constituía-se em um saber operacional que ignorava a anteposição filosófica (STRECK, 2009b, p. 67), com o que edificava uma filosofia própria para o direito (STEIN, 2004, p. 137) incapaz de trazer os mesmos vetores racionais da hermenêutica filosófica.

A hermenêutica filosófica, ao movimentar-se em plano distinto do direito, com sua fenomenologia do conhecimento (STRECK, 2008, p. 156-167), possui capacidade transcendental ordenatória da base científica de correção do discurso científico (STEIN, 2004, p.127). Essa transcendência da filosofia (STEIN, 2004, p.149) é capaz de fazer "sangrar conceitos plenipotenciários do Direito" (STRECK, 2009b, p. 67). Isso não importa, todavia, na imposição

2 Onde a linguisticidade é sempre anterior a qualquer compreensão, impedindo que os sentidos possam ser alcançados independentemente do ser, como na premissa da objetivação do mundo, configuradora da relação sujeito-objeto". (GADAMER, 1999, p. p. 653). 
filosófica de respostas para os problemas jurídicos, não há cooptação do objeto do direito, na medida em que a transcendência hermenêutica filosófica não é englobante de todas as formas de saber (STEIN, 2004, p. 130-139). No entanto, a tarefa não é simples, exigindo a capacidade de leitura de ambos os discursos, de modo a impedir a transposição equivocada de fala (STEIN, 2004, p. 127-128).

É reconhecida a autonomia do direito em face da hermenêutica filosófica. O Direito não pertence à hermenêutica filosófica, da mesma forma que a hermenêutica não pertence ao Direito. Nenhuma das duas pode evocar o objetivo de desvendamento de todos os saberes humanos. A interpretação é imanente ao ser na sua experiência de mundo e, a partir disso, é que surge a possibilidade da experiência científica. Incindíveis são a experiência ontológica e científica, sendo, a primeira, condição de possibilidade da segunda, denunciadora dos planos distintos em que transitam (STEIN, 2002, p. 102). É admissível, dessa maneira, que cada um dos saberes desenvolva critérios próprios, intrínsecos, de comprovação e refutação de seus enunciados (STEIN, 2004, p. 139), porém com a capacidade de diálogo exposta. Antes de ser prejudicial, a hermenêutica filosófica é capaz de reforçar o discurso jurídico, em face da libertação dos paradigmas filosóficos anteriores (STRECK, 2008, p. 133).

A ausência de pontos de contato entre filosofia e direito, a carência da transcendência, foi produtora de um direito ora metafisicamente objetivista, ora subjetivista (STRECK, 2009b, p. 67). No artigo e na decisão analisada é proposta a ultrapassagem dessa problemática com a adoção de uma perspectiva de Constituição viva e sentida (VERDÚ, 2004, p. 7-8) hermeneuticamente no dasein (VÉLEZ, 2006, p. 40), em um ser não encapsulado (HEIDEGER, 2009, p. 128), onde a produção e limitação de sentidos decorre da tradição e da realidade histórica (GADAMER, 1999, p. 415-416). Inadmissível, portanto, sentidos objetivados, unívocos, que são independentes do sujeito ou verdades arbitrárias, exclusivamente subjetivas. Os sentidos derivam do advento linguístico, considerando o homem em sua contextualidade histórica e temporal, no dasein. 0 tempo, a historicidade, são limitadores de sentidos do ser, justificando a conhecida expressão gadameriana de que o homem é "filho do seu tempo" (GADAMER, 1999, p. 577), tornando inevitável o reconhecimento da finitude do ser-homem, da consciência histórica (GADAMER, 1999, p. 444).

$\mathrm{Na}$ decisão é assumido o pressuposto de níveis diversos do jurídico e do hermenêutico filosófico. Não há resposta pré-dada, mas uma construção constitucional amoldada ao caso concreto. De modo que, não há na solução judicial nem a objetividade da aplicação das regras legais e nem uma aplicação solipsista, mas limitada temporalmente e contextualmente, baseada na Constituição, capaz de inserir por meio do intérprete, sem resvalar para o arbítrio, o delineamento necessário do interesse social e democrático no direito.

\section{A ABERTURA LINGUÍSTICA E OS MÉTODOS INTERPRETATIVOS}

A interpretação como instrumento para alcançar sentidos imanentes ao texto legal tem íntima vinculação com o postulado platônico ou neoplatônico de correspondência de nome e essência (CASSIER, 1992, p. 17). No entanto, esse liame e a universalidade de sentidos 
decorrentes são metafísicos, pressupondo um mundo ideal acessível aos homem e/ou uma transposição de vivências e pré-compreensões. Inexiste universalidade de sentidos, uma interpretação nunca é igual a outra, ainda que o objeto da interpretação seja o mesmo (HEIDEGGER, 2009, p. 94). O giro-linguístico importou no "apalavreamento" do mundo (VÉLEZ, 2006 , p. 40), transformadora da própria condição humana (ZEA, 2010, p. 9). Não que o mundo e as coisas não subsistam sem o homem (HEIDEGGER, 2009, p. 77 e GADAMER, 1999, p. 649), mas que as significações estão na existência do homem, no dasein, consistindo em apreensões da coisa que nunca serão a coisa em si, mas que consistem no limite de mundo do homem (HEIDEGGER, 2009, p. 75). Os sentidos de mundo, qualquer um deles, advém ao ser pela linguagem, com o que os sentidos não estão no ente, mas no ser, todavia não como propriedade do indivíduo, na sua singularidade, pois o dasein é um desvelamento compartiIhado (HEIDEGGER, 2009, p. 127). O compartilhamento permissor da capacidade comunicativa exige um colocar-se de acordo sobre a coisa (GADAMER, 1999, p. 559-560), porém sem respaldar o sonho objetivista de equivalência de palavras e coisas, mas aceitando um vínculo interno entre palavra e coisa (GADAMER, 1999, p. 587).

Na compreensão do texto, especificamente, não pode ser diferente. 0 segundo Wittgenstein abandona o rigorismo da convencionalidade de sentidos para equiparar o apalavramento das coisas ao ato de etiquetar uma coisa ( WITTGENSTEIN, 1994, p. 32), posto que as convenções linguísticas são incapazes de trazer a realidade (OLIVEIRA, 1996, p. 128). O colocar-se de acordo com o texto permissor da sua compreensão, pressupondo essa convencionalidade comunicativa, ampara inevitáveis ambiguidades, porquanto há apenas semelhanças e aproximações, onde o uso das palavras não encontra fronteiras, o que, por outro lado, não implica em ausência de significado (OLIVEIRA, 1996, p. 130), já que as semeIhanças e parentescos no dasein são impeditivas do arbítrio de sentidos (OLIVEIRA, 1996, p. 131). A filtragem hermenêutica de sentidos arbitrários é impeditiva da ausência de significados, inviabilizadora da comunicação, do colocar-se de acordo. A hermenêutica filosófica desvela tanto a inapropriação de mundo pela linguagem, autorizativa do arbítrio de sentidos pelo intérprete, quanto a objetivação de mundo, com sentidos advindos exclusivamente do texto, independentes do ser contextual e histórico (GADAMER, 1999, p. 653).

A interpretação como método está inserida na crítica da objetivação e da subjetivação referidas, contrapostas pela linguagem que introduz o ser no mundo (OLIVEIRA, 1996, p. 127), pela hermenêutica como existencial do ser histórico, como experiência de mundo (VATTIMO, 1987, p. 155), local em que interpretar é compreender (GADAMER, 1999, p. 566) e aplicar é a expressão sensível do pensamento (OLIVEIRA, 1996, p. 107), fazendo ruir a separação positivista de compreensão, interpretação e aplicação para ser desvelada a sua unidade (GADAMER, 1999, p. 460). Há negação do caráter instrumental da interpretação, com a viragem linguística, quando a linguagem é condição de possibilidade da compreensão (OLIVEIRA, 1996, p. 128). A linguagem, a interpretação e a compreensão são vetores que mais proximamente esclarecem a metafísica da objetivação e engessamento de sentidos, enquanto que a racionalidade da aplicação adquire especial relevo no controle da subjetividade solipsista, vedando seu relativismo (STRECK, 2015, p. 99).

O positivismo jurídico concebe sentidos pré-dados no texto legal, pressupondo sentidos independentes do ser (STRECK, 2008, p. 128). O jurista utiliza o instrumento técnico da interpretação e, se o método for adequado, com a compreensão e aplicação corretas, 
atinge resultados objetivos e universais (STRECK, 2009b, p. 67-68). A linguagem era metafisicamente apartada do conhecimento, da interpretação, estruturando a relação linguagem-objeto, com a possibilidade inclusive de supressão da linguagem para a compreensão, como na premissa platônica mencionada (BARTHES, 1987, p. 20). A metafísica é revelada por Gadamer (1999, p. 566) quando reconhece a universalidade da linguagem, constituindo-se em condição do ser, sem a qual não há interpretação, não há compreensão, não há acesso ao mundo . A objetivação positivista na adjudicação de sentidos é superada pela processo linguístico de compreensão e interpretação, pois a "linguagem é o médium universal em que se realiza a própria compreensão. A forma de realização da compreensão é a interpretação (GADAMER, 1999, p. 566). De modo que, o objeto (o seu sentido) só o é ou pode chegar a ser pela linguagem, interpretação e compreensão (GADAMER, 1999, p. 588-589), no "ser-sentido-linguagem" (VÉLEZ, 3006, P. 40).

Em outro momento, o direito submeteu-se à filosofia da consciência onde o sujeito é superdimensionado, alcançando uma posição centralizadora de domínio intelectual, o que lhe permite assumir um relativismo em relação às coisas e assujeitar os sentidos (STRECK, 2014, p. 54). Foi dito que no processo unitário interpretativo, a aplicação impõe a contextualidade fática do ser, resultando na tradição hermenêutica filosófica, na historicidade, impeditivas da escolha de sentidos do ser, apoio no qual o ser desenvolve sua verdade e sua liberdade (OLIVEIRA, 1996, p. 220). Em assim sendo, as significações decorrem da janela linguística, do círculo hermenêutico, amalgamadas à tradição. A produção de sentidos decorre da consciência histórico-efeitual. Na leitura do texto, inclusive o jurídico, os pressupostos mencionados são responsáveis pelo novo sentido do escrito, distante da objetivação (STRECK, 2009a, p. 222) e da subjetivação, pautando os sentidos em seu caráter construtivista histórico (STRECK, 2009a, p. 215). Há um esforço exigível do intérprete para o desvelamento de qualquer fenômeno (HEIDEGGER, 2009, p. 73), não para alcançar o sentido objetivado, mas para não ser conduzido pela subjetivação, para não permitir respostas apartadas da história e da temporalidade, desencarnadas de um caso concreto histórico, cultural e determinado (VÉLEZ, 2006, p. 49). Há uma correspondência entre a subjetividade e a objetividade na linguagem, no seu recíproco pertencimento, não permitindo que a experiência aconteça de qualquer forma diversa (OLIVEIRA, 1996, p. 247).

A filosofia da consciência no direito ignora os postulados hermenêutico filosóficos referidos. Inviável é o reconhecimento de um saber dominador do jurista intérprete, de uma capacidade de apropriação e apoderamento do escrito posto, inclusive do legal. Muito diferente disso, há uma submissão do jurista intérprete à pretensão dominante do texto (GADAMER, 1999, p. 464). O decisionismo antidemocrático, onde as soluções jurídicas obedecem critérios exclusivamente subjetivos do órgão julgador (ENGELMANN, 2001, p. 71), muitas vezes, especialmente na contemporaneidade, encontram na aplicação dos princípios sua válvula de escape, seu manto de encobrimento. Esse tipo de "aplicação" principiológica resulta em uma incontrolabilidade e inaceitabilidade (ENGELMANN, 2001, p. 167-168), quando, na perspectiva do artigo, o direito e a constituição é que devem ditar o limite democrático da atuação judicial (STRECK, 2015, p. 107-108). 


\section{A NORMATIZAÇÁO CONSTITUCIONAL NO CASO ESTUDADO}

O caso concreto parte da premissa da hierarquia constitucional (LEAL, 2006, p.1565) e do fortalecimento da Constituição (HOMMERDING, 2007, p. 27). A perspectiva constitucional em estudo não traz uma supervalorização do texto legal, equiparando lei e direito, tendo o legislador como único legítimo produtor do direito (GROSSI, 2003, p. 64) e o juiz como mero boca da lei. Há a fuga de uma aposta kantiana em um legislador que tudo pode, por ser supostamente a representação da vontade do povo (BODENHEIMER, 1966, p. 80-81). É o Judiciário que ganha destaque na concretização constitucional do caso concreto (HÖFFE, 2003, p. 69-70). Não em um subjetivismo exacerbado e incontrolável (STRECK, 2014, p. 53), mas em limites contextuais e temporais, hostilizando, hermeneuticamente, tanto a objetividade paralisante quanto a subjetividade arbitrária.

A objetividade da lei fez surgir a crença na subsunção, onde o grande objetivo do direito deveria estar centrado na clareza da lei, para a "aplicação literal", trazendo como consequência a estagnação, a incapacidade de amoldamento às variáveis do mundo da vida, criando injustiças (GARCÍA-HUIDOBRO, 2002, p. 106-107). Aliás, a subsunção e o método interpretativo são duas faces da mesma moeda, da moeda da objetivação de sentidos (STRECK, 2009a, p. 310). A objetivação de sentidos é geradora de dogmas inquebrantáveis, onde o intérprete, consciente ou inconscientemente, ao procurar a voz (o sentido) da lei, acaba escutando unicamente a sua própria voz (TODOROV, 1991, p. 149), fazendo reverberar o eco da fala autorizada (AROCA, 1999, p. 16). Há nesse habitus jurídico uma crença no alcance de sentidos de forma acontextual (DWORKIN, 2009, p. 23), para a qual deve ser relembrada a crítica da entificação da linguagem, que redunda na falta de percepção da diferença ontológica (STEIN, 2002, p. 100). 0 engessamento do direito, diante dos predicativos criticados, torna-se inevitável, obstando o fim constitucional e democrático do direito.

O estudo traz a percepção de que não é admissível a mera reprodução mecânica do direito, como ocorreria na atividade subsuntiva, pois toda interpretação é produtiva. Inapropriada, portanto, a classificação positivista de aplicação por subsunção para normas expressas e, na ausência dessas, a situação excepcional de integração e/ou produção do direito (GUASTINI, 2005, p. 43). A aposta na objetividade e na aplicação subsuntiva da lei para produzir os sentidos aplicáveis no caso concreto, com tolerância para a razão prática nos caso sem previsão legal, redundou em uma produção epistemológica consciente de sua incapacidade para abarcar todos os fatos da vida, provocando uma rachadura no direito com a admissão do alvitre judicial (STRECK,, 2015, p. 107-108).

Indispensável a subjetividade na adjudicação de sentidos, porém não de forma incontrolável, como no arbítrio judicial. 0 giro linguístico-hermenêutico reivindica o ser para a obtenção de sentidos, portanto, forçoso que ocorra no direito, na atividade jurisdicional, a construção da norma, com atenção para a diferença ontológica, para o descortinamento fenomenológico, em uma harmonia constitucional e democrática (VERDÚ, 2004, p. 6-7), no plano apofântico do direito. 0 direito não fica refèm nem do imobilismo positivista-legalista e nem da razão prática, havendo uma mobilidade limitável, apta a atender a mutabilidade da sociedade, os seus cambiantes contornos sociais (VILLEY, 2007, p. 51-52), (exclui) em um piso de progressividade racional, inclusive, quando necessária, de natureza contramajoritária 
para atender ao fim democrático (BODENHEIMER, 1966, p. 71), sem apostar em uma superioridade moral e intelectual subjetiva (HÖFFE, 2005, p. 127).

As especificidades locais ficaram bem evidentes com a pandemia, a exigir a normatização constitucional não engessada, atenta para as mesmas, trilhando o caminho da concretização constitucional, da constituição real (HESSE, 1991, p. 9-21). A observância das peculiaridades, como ocorreu na decisão em estudo, demonstram a mobilidade constitucional desejada do direito, apta a evitar injustiças, consistentes no descolamento do fático e do social. A desejada capacidade de acompanhamento do fático, por outro lado, (modifiquei) não podem ir além dos limites jurídico e constitucionais. Então, é indubitável que a atividade jurisdicional é de construção subjetiva da norma, dentro dos padrões constitucionais, considerando as diferenças essenciais de cada situação fática posta em análise no processo (STRECK, 2009b, p. 76).

Na decisão em estudo é possível perceber que a normatização ocorreu respeitando o texto legal, indo diretamente nos dispositivos textuais municipais, permitindo que ele dissesse algo, distante de opiniões prévias de sentidos, buscando a sua legitimação (GADAMER, 1999, p. 403) na presença de uma dialética constitucional. Nessa interação não foram ignorados os interesses constitucionais postos em jogo na facticidade temporal, diante da pandemia, na situação específica da controvérsia, sobre a possibilidade de ser permitida ou não a realização de atividades (tele-entrega e pegue-leve), no shopping, quando a determinação geral era de proibição de funcionamento de shopping e autorização das duas espécies de serviços nos demais restaurantes. A normatização constitucional e democrática, na conjuntura exposta, permitiu exclusivamente o funcionamento da tele-entrega para atender a isonomia constitucional e preservar o interesse social de controle da pandemia, envolvendo o direito à vida e à saúde. A atividade judicial, portanto, muito distante de tentar substituir a atividade do legislador ou do administrador público, de confiar em um ativismo judicial, trouxe a solução jurídica adequada na temporalidade constitucional (STRECK, TASSINARI, LEPPER, 2015, p. 52-62), considerando a incessante mutabilidade social (CHAUÍ, Marilena, 1983, p. 7), acentuada em tempos de pandemia, onde as peculiaridades regionais, mormente em face da eventual maior ou menor eficácia dos mecanismos de controle, são determinantes das limitações convenientes.

\section{CONCLUSÃO}

0 artigo estudou a decisão judicial que determinou o funcionamento do serviço de tele-entrega de restaurante em shopping center. Foram considerados os regramentos municipais que não disciplinavam especificamente a situação enfrentada na decisão, não para uma aplicação por subsunção, mas sim para a normatização no caso concreto, em dialética constitucional envolvendo liberdade e igualdade do direito de comerciar com o risco à vida e à saúde da população, na presença da pandemia.

O giro-linguístico permitiu o reconhecimento de uma condição anterior hermenêutica filosófica, com capacidade transcendental ordenatória, apta a contribuir para o aperfeiçoamento do direito, permitindo a reconexão fenomênica, especialmente no caso do artigo, 
trazendo a relevância do tempo e da história na construção do jurídico, sem recorrer à razão prática. Essa interação pressupõe a autonomia de filosofia e direito, com objetos distintos, mas com a possibilidade de adjudicação de saberes, em razão do compartilhamento do mundo vivido. É abandonada, portanto, a perspectiva da incomunicabilidade de filosofia e direito, bem como a de setorização da filosofia, como na admissão da filosofia do direito.

Há na normatização constitucional no caso concreto sugerida no escrito uma elevação do papel constitucional, não mais apenas como texto escrito, mas sobretudo viva na sociedade, nos cidadãos. A viragem linguística traz o despertar do sonho positivista de encapsulamento de sentidos nas linhas do texto legal, em face do adjudicamento de sentidos da inafastabilidade linguística, do dasein. Nisso está a indispensabilidade do ser para a obtenção de sentidos, porém em um fechamento para o arbítrio, decorrente da tradição e historicidade, da temporalidade do homem e da consciência histórica, que permite, ao Judiciário, o desempenho do papel de guardião da Constituição e da democracia na contemporaneidade.

A interpretação não é um método para alcançar sentidos universais. Não há equivalência entre palavras e coisas. 0 círculo hermenêutico mostra que uma interpretação nunca é igual a outra, ainda que haja identidade de objeto interpretado. As apreensões além de serem sempre diversas também nunca serão a coisa em si, defronte da intermediação linguística, em que o mundo advém ao ser pela linguagem. Situação que não autoriza o ser apropriar-se do mundo, na medida em que é ser no mundo, ser com outros, a exigir um compartilhamento de sentidos, permissor, inclusive, da capacidade comunicativa do homem.

As convenções linguísticas da comunicação textual, com relevância para o jurídico, são incapazes de restaurar a correspondência platônica de objeto, de mundo. 0 intérprete deve cumprir a tarefa de colocar-se de acordo, em que pese lide apenas com semelhanças e aproximações dessas convenções linguísticas, com inevitáveis imprecisões. 0 avizinhamento de sentidos e o dasein permitem a completude significativa textual no ser. No plano jurídico, é exigível o esforço dialético epistemológico das regras infraconstitucionais e constitucionais para o desentramento hermenêutico, apto a conectar a decisão contextualizada ao objetivo democrático, tendo a interpretação, a compreensão e a aplicação como evento único.

A supremacia constitucional defendida coloca em destaque a atuação judicial na sua concretização, sem aderir a um subjetivismo abusivo. A Constituição deixa de ser mero texto legislativo para ser norma em situações vividas. Deixa para trás a crença jurídica na subsunção, nos métodos interpretativos e na razão prática, permitindo um conteúdo substancial constitucional transformador da realidade, racionalmente progressivo, em face de eventuais situações de perversidade na manutenção do status quo. De modo que o direito escapa do aprisionamento legalista e da insegurança judicial solipsista. No estudo e na decisão em comento são assumidos, no dasein, uma mobilidade, indispensável, notadamente para o momento de agravamento de crises sociais decorrentes da pandemia do coronavírus, ao mesmo tempo em que são estabelecidas barreiras consistentes no respeito de construções jurídicas legítimas, mormente do texto legal, mas sem perder a capacidade de persecução dos fins progressivos racionais democráticos. 


\section{REFERÊNCIAS}

AROCA, Juan Montero. Introducción al Derecho Jurisdiccional peruano. Lima: Enmarce,1999.

BARTHES, Roland. El susurro de lenguaje más allá de la palabra y de la escritura. $1^{\text {a }}$ ed., Barcelona - Buenos Aires- México: Paidós, 1987.

BODENHEIMER, Edgar. Ciência do Direito. Filosofia e metodologia jurídicas. Tradução de Enéas Marzano. Rio de Janeiro: Editora Forense, 1966.

BONAVIDES, Paulo. Teoria constitucional da Democracia Participativa. 3a ed. São Paulo: Malheiros, 2003.

CASALINI, Brunella. Costa, Pietro e Zolo, Danilo (orgs.). O Estado de Direito. História, teoria, crítica.

Paulo: Editora Martins Fontes, 2006.

CASSIER, Ernst. Linguagem e mito. São Paulo: Editora Perspectiva. $3^{a}$ edição, 1992.

CHAUÍ, Marilena. A invenção democrática. In LEFORT, Claude. Trad. De Isabel Marva Loureiro. São Paulo: Brasiliense, 1983.

DAMASKA, Mirjan. Las caras de la justicia y el poder del Estado. Análisis comparado del Proceso Legal. Santiago: Editorial Jurídica de Chile, 2000.

DWORKIN, Ronald. O império do Direito. $1^{\text {a }}$ Ed. São Paulo: Martins Fontes, 2009.

ENGELMANN, Wilson. Crítica ao Positivismo Jurídico. Princípios, Regras e o Conceito de Direito. Porto Alegre: Sérgio Antonio Fabris Editor, 2001, p. 167.

FERRAJOLI, Luigi. Costa, Pietro e Zolo, Danilo (orgs.). O Estado de Direito. História, Teoria, Crítica. São Paulo: Martins Fontes, 2006.

GADAMER, Hans-Georg. Verdade e método.Vol. 1. $3^{\text {a }}$ ed. Petrópolis: Vozes, 1999.

GARAPON, Antoine. O juiz e a democracia: o guardião das promessas. 2a ed. Tradução de Maria Luiza de CarvaIho. Rio de Janeiro: Revan, 1999.

GARCÍA-HUIDOBRO, Joaquin. Filosofia y retórica del iusnaturalismo. Mexico: Universidad Nacional Autónoma de México. Instituto de Investigaciones Jurídicas, 2002.

GROSSI, Paolo. Título original: Mitologie giuridiche della modernità. Madri: Editorial Trotta. Giuffrè Editore. Manuel Martínez Neira, 2003.

GUASTINI, Ricardo.Das fontes às normas. Tradução: Edson Bini. São Paulo: Editora Quartier Latin do Brasil, 2005.

HABERMAS, Jürgen. A Inclusão do Outro. Estudos de Teoria Política. Tradução: George Sperber e Paulo Astor Soethe Edições Loyola, 2002.

HABERMAS, Jürgen. Jürgen Habermas fala a Tempo Brasileiro. In: Revista Tempo Brasileiro. Vol. 5, $\mathrm{n}^{\circ} 21$. Rio de Janeiro: Tempo Brasileiro, ed. trimestral, 1989.

HEIDEGGER, Martin. Introdução à Filosofia. São Paulo: Martins Fontes, 2009.

HESSE, Konrad. In: A força normativa da Constituição. Tradução de Gilmar Ferreira Mendes. Porto Alegre: Fabris, 1991.

HÖFFE, Otfried. A democracia no mundo de hoje. Trad. Tito Lívio Cruz Romão. São Paulo: Martins Fontes, 2005. HÖFFE, Otfried. O que é Justiça? Tradução: Peter Naumann. Coleção: Filosofia - 155. Porto Alegre: Edipucrs, 2003. HOMMERDING, Adalberto Narciso. Fundamentos para uma compreensão hermenêutica do Processo Civil. Porto Alegre: Livraria do Advogado, 2007.

JESSUA, Claude. Capitalismo, Coleção L\&PM Encyclopaedia. Tradução: William Lagos. 2013.

LEAL, Mônia Clarissa Hennig. In: REIS, Jorge Renato; LEAL, Rogério Gesta. Direitos Sociais e políticas Públicas: Desafios Contemporâneos. Tomo 6. Santa Cruz do Sul: EDUNISC, 2006. 
OLIVEIRA, Manfredo Araújo de. Reviravolta lingüistico-pragmática na Filosofia Contemporânea. São Paulo: Edições Loyola, 1996.

RUFFLA, Paolo Biscaretii. Democracia. Enciclopédia Del Diritto. Guffià editore, 1960.

STEIN, Ernildo. Exercícios de fenomenologia: Limites de um paradigma. Parte III ljuí: Unijuí, 2004.

STEIN, Ernildo. Pensar é pensar a Diferença. Filosofia e conhecimento empírico. ljuí: Editora Unijuí, 2002.

STEINER, George. Pasión intacta. Santafé de Bogotá: Ediciones Siruela, 1997.

STRECK, Lenio Luiz. Aplicar a "Letra da Lei" é uma atitude positivista? Novos Estudos jurídicos. Revista Novos Estudos Jurídicos. V.15, n.1, 2010. Disponível em: www.univali.br/periódicos, p. 158/173.

STRECK, Lenio Luiz. Hermenêutica e Possibilidades Críticas do Direito: Ensaio sobre a cegueira positivista. Revista Faculdade de Direito UFMG. Belo Horizonte, nº 52, jan/jun., 2008.

STRECK, Lenio Luiz. Hermenêutica jurídica $e(m)$ crise: uma exploração hermenêutica da construção do direito. $8^{a}$ ed. rev. atual. Porto Alegre: Do Advogado, 2009a.

STRECK, Lenio Luiz. Jurisdição constitucional e hermenêutica. Uma nova crítica do direito. $2^{\mathrm{a}}$. ed. Rio de Janeiro: Editora Forense, 2004.

STRECK, Lenio Luiz. O que é isto - Decido conforme minha consciência. $5^{\mathrm{a}}$ ed. Porto Alegre: Livraria do Advogado, 2015.

STRECK, Lenio Luiz. Verdade e consenso: Constituição, hermenêutica e teorias discursivas. 5a ed. São Paulo: Saraiva, 2014.

STRECK, Lenio Luiz. Hermenêutica, Constituição e autonomia do Direito. Revista de Estudos Constitucionais, Hermenêutica e Teoria do Direito. Janeiro-Junho, 2009b.

STRECK, Lenio Luiz; Tassinari, Clarissa; Lepper, Adriano Obach. In: 0 problema do ativismo judicial: Uma análise do caso MS3326. Revista Brasileira de Políticas Públicas. Volume 5, Número Especial, 2015.

TODOROV, Tzvetan. Crítica de la Crítica. $1^{\text {a }}$ ed., Traducción de José Sánchez Lecuna. Barcelona, Buenos Aires, México: Ediciones Paidos, 1991.

VATTIMO, Gianni. El fin de la Modernidad. Nihilismo y hermenéutica en la cultura posmoderna. $2^{\mathrm{a}}$ ed., Colección Hombre Y Sociedad. Serie Mediaciones. Traduccion: Alberto L. Bixio. Barcelona: Editorial Gedisa S. A., 1987.

VÉLEZ, Julio César Barrera. Hermenêutica analógica: paradigma del pensar latinoameircano. Contextos de la hermenéutica analógica. $1^{\text {a }}$ ed. Ricardo Blanco Beledo (Compilador). México: Editorial Torres Asociados, 2006.

VERDÚ, Pablo Lucas. O Sentimento constitucional. Aproximação ao estudo do sentir constitucional como modo de integração política. Tradução: Agassiz Almeida Filho. Rio de Janeiro: Editora Forense, 2004.

VIANNA, Luiz Werneck; CARVALHO, Maria Alice Rezende; MELO, Manuel Palacios Cunha; BURGoS, Marcelo Baumann. A judicialização da política e das relações sociais no Brasil. Rio de Janeiro: Editora Revan, 1999.

VILLEY, Michel. O Direito e os Direitos Humanos. Tradução: Maria Ermantina de Almeida Prado Galvão. São Paulo: Martins Fontes, 2007.

WITTGENSTEIN, Ludwig. Investigações filosóficas. Petrópolis: vozes, 1994.

ZEA, Leopoldo. La Filosofía americana como Filosofía sin más. Novena reimpresión. México: Siglo Veintituno Editores, 2010.

Recebido/Received: 26.05.2020.

Aprovado/Approved: 12.06.2020. 